\title{
Language diversity management in higher education: towards an analytical framework
}

\begin{abstract}
Linguistic diversity and its management have become increasingly significant for higher education institutions around the world. Indeed, in the context of a growing student and staff mobility, information exchange, and networked multilateral interactions, the multiplicity of languages used by university stakeholders in more and more contexts has steadily grown over the past decades. A wide range of scholars (from applied and sociolinguists to higher education researchers) have responded with an equal growing attention to this phenomenon. In this paper, we funnel some of the relevant recent scholarship on the language-planning dimension of the internationalization of higher education, providing as a result an analytical framework that attempts to capture the complex sociolinguistic nature of present-day universities. To date, with only a handful of exceptions, few attempts have been made to provide a comprehensive overview of the different levels, stakeholders, and contexts of language use in higher education. Given the rapid changing nature of language matters in such context, the framework we present in this paper should be useful to both sociolinguists interested in language issues in higher education and to on-the-ground university administrators actively engaged in language planning initiatives in their institutions. The framework, however, is not conceived of as a closed-end solution to language problems at universities today, but rather as a guiding roadmap to think productively about such issues.
\end{abstract}

Keywords: Language policy and planning, linguistic diversity, language management, higher education, analytical framework

\section{Introduction}

The management of linguistic diversity in higher education is a topic that has been given considerable attention over the past years. Quite often, however, scientific discourse tends to concentrate on the weight of certain languages (especially English) in

\footnotetext{
Jeroen Darquennes, Namur institute of Language, Text and Transmediality, Université de Namur, Rue de Bruxelles 61, B-5000 Namur, Belgium, jeroen.darquennes@unamur.be Theo du Plessis, Department of South African Sign Language and Deaf Studies, University of the Free State, 205 Nelson Mandela Drive, Bloemfontein 9300, Republic of South Africa, dplesslt@ufs.ac.za Josep Soler, Department of English, Stockholm University, SE-106 91 Stockholm, Sweden, josep.soler@english.su.se
} 
publications and university teaching, the legal frameworks and the language-in-education policies developed to deal with linguistic diversity at university level, or to pedagogical questions addressing language teaching principles and methods. Much less attention seems to be devoted to the study of linguistic diversity management in higher education as a process that covers the design, the implementation as well the evaluation of language policies aiming at (re)affirming or changing the language dynamics in a variety of domains within a particular institution of higher education in a certain geographical setting. Rather than focusing on every single detail of the management process, this chapter seeks to offer a broader take on the process of language diversity management in higher education. It presents a framework that is meant to serve as a guidepost for those interested or actively involved in the design, implementation and/or evaluation of language policy and planning initiatives at present-day universities. The framework is the result of a systematic analysis of secondary literature on language policy and planning (LPP) in higher education. The analysis of the nature of language policies in higher education is preceded by a brief discussion of the emergence of language diversity management (as part of university governance) on university agendas mainly since the second half of the 20th century. To start with, this chapter offers a non-exhaustive overview of topics in current literature on language diversity management in higher education, topics that will reappear in the section devoted to the framework.

\section{Literature on linguistic diversity management in higher education}

Recent publications such as Haberland/Mortensen (2012), Cots/Llurda/Garrett (2014), Vila/Bretxa (2015), Liddicoat (2016), Soler (2019) and Soler/Gallego-Balsà (2019) altogether offer quite an extensive overview of literature that deals with language (diversity) management in higher education. It is, therefore, not our intention to (re)produce an exhaustive literature overview on the basis of these and other equally valuable publications. For the purpose of this chapter, we restrict ourselves to a number of broad topics that are dealt with in applied linguistics, sociolinguistics and educational linguistics:

- Literature on language teaching (practices) in higher education touches upon a diversity of issues covering not only the use of 'languages for specific purposes' (e.g. Van de Poel et al. 2015; Hyland/Shaw 2016), but also models of bi/multilingual university education (e.g. Purser 2000; van Leeuwen/Wilkinson 2003; du Plessis 2006; van der Walt 2013), the measurement of students' literacy skills (e. g. D’Hertefelt/De Wachter/Verlinde 2014; du Plessis 2016), and the implementation of the Common European Framework of Reference at the level of university language teaching in Europe and beyond (e.g. Martyniuk 2010). 
- Because of the increasing attention that has been given to student mobility over the past decades (Charle/Verger 2012), more and more studies are available on study abroad programs and the effects they have on students (Block 2016). The mission statement of the journal Study Abroad Research in Second Language Acquisition and International Education (John Benjamins) gives a good overview of the topics dealt with in this branch of applied linguistics. When it comes to language learning, its contributions "explore all facets of second language acquisition during study abroad such as the nature of linguistic development, input engagement and interaction, and the role of contextual, social and socio-biographical factors underpinning the learner's experience abroad". Next to that, the journal welcomes contributions that explore "issues beyond the linguistic, such as the relationship between study abroad and academic, professional, personal and social development”. Yet another area of focus “is educational policy and planning issues in study abroad exchange programmes within international education" (see benjamins.com/catalog/sar, accessed on 19 March 2020).

- There is a growing amount of literature that devotes attention to what is referred to as the peregrinatio academica in Early Modern Europe (e.g. Kiedron 1992; Frank-Van Westrienen 1983; Irrgang 2002). Special attention is devoted to different sorts of language practices of members of the so-called Republic of Letters (i. e. the long-distance network of scholars that existed in Early Modern Europe). This kind of literature helps to remind us that "the idea of the itinerant scholar is one that predates the founding of universities as educational institutions" and that "foreign students and foreign academics were an indispensable part of the earliest universities" (Liddicoat 2016: 231, with reference to Welch 2005).

- An important share of the existing literature on language management in higher education focuses on the (changing) status of national languages as scientific languages. Ground-breaking work has been done here by Ammon $(1988,1998,2001)$ who focused on changes in the scientific status of German as well as English. More recent work includes Gordin (2015) who provides an historians' take on the languages of science from the fall of Latin to the rise of English and Gazzola's (2012) study on the linguistic implications of academic performance indicators.

- The recent focus on the role of language (especially English) in the marketization of universities as both global and local players (see e. g. Björkman 2013; Jenkins 2013) can, at least in part, be considered as a continuation of a research line developed by Norman Fairclough in the early 1990s. Fairclough (1993: 143) noted that higher education institutions tend "to operate (under government pressure) as if they were ordinary businesses competing to sell their products to consumers". He spurred on the critical analysis of the discourses on the internationalization of universities and the role that languages play in such discourses. The creation, interpretation and appropriation of such discourses by a multitude of social agents that play a key role in the management of linguistic diversity is at the heart of contemporary studies that focus on the internationalization of higher 
education from the point of view of the ethnography of language policy (e.g. Hult 2016; Soler 2019; Soler/Gallego-Balsà 2019).

- Of course, the larger debate about the "internationalization" (or perhaps: transnationalization; see Haberland/Mortenson 2012: 1) of universities as a by-product of globalisation as such has been receiving attention. The director of the English in Europe Project alludes to the fact that English actually has become the "biggest language challenge in the world today" (Linn 2015: vii), requiring a targeted language management approach. Bergan (2002) edits one of the first publications that deal with a language policy and planning response to this evolving challenge. Barnard/McLellan (2013), Hultgren/Gregersen/Thøgersen (2014) and Hult (2016) relate to the latter and look in depth at how to manage such demands specifically in higher education in the Nordic countries. However, Haberland/Mortenson (2012: 1) warn that internationalization does not necessarily imply Anglicization per se, implying a more mosaic challenge to managing language diversity at university level. Consequently, Vila/Bretxa (2015) choose to focus on the challenge of internationalization for "linguae academicae other than English," [own emphasis] so as to counter the adverse effects of "Englishization" or Anglicization.

- Although somewhat overshadowed by the demands posed by the latter, the growing phenomenon of bi- and multilingual universities represent a managed multilingual response in dealing with the challenges of internationalization. Veronesi/Nickenig (2009) specifically focus on the implications for language policy and planning of establishing such universities. This of course builds on the work of Purser (2000) and others contributing to the movement in establishing bi- or multilingual universities. See also Mansoor (2005) and Du Plessis (2006).

- Also often rooted in critical discourse analysis is research on the kind of language ideologies that prevail at universities in 'postcolonial settings'. Growing attention is given to campaigns against racism at universities (i. e. campaigns such as 'Rhodes must fall' and 'Steyn must fall' in South Africa, 'Why is my curriculum white?' in the UK) as well as to the way in which ethnic minority students “find themselves under-represented and under-estimated by the content of their curricula, with their histories, narratives, and experiences omitted from mainstream discourse” (Soler/Gallego-Balsà 2019: 23; see also Bhambra/Gebrial/Nişancığlu 2018).

The attention given to language policy issues in higher education in sociolinguistics, applied linguistics and educational linguistics is not only the result of a proliferation of language policy studies tout court (see Darquennes 2013; Tollefson/Perez-Milans 2018). It also is the result of the fact that, over the past decades, a growing number of universities have engaged in developing policies and regulations in a great variety of domains including teaching, research, communication, ethics, student life, etc. 


\section{Language diversity management as part of university governance}

Many studies exist that document and analyze (changes in) the missions and the governance of universities all over the globe (see e. g. Rüegg 2011; Austin/Jones 2016; Curaj/Deca/Pricopie 2018). Research that focuses on university governance from the 2nd half of the 20th century onwards indicates that the growth in number of universities and students seems to have gone hand in hand with universities becoming rapidly more diverse (in terms of the students' and the staff members' backgrounds and the programs offered), a stronger link with business and society, and a "managerialism wave" meaning, among other things, that there has been a "considerable organizational growth far beyond the faculty ranks - in a wide array of new administrative, service, and management posts” (Frank/Meyer 2007: 21).

While it goes without saying that there are often substantial differences between and within continents and countries, it still seems safe to say that there has been a proliferation of regulations and policies in a growing variety of often interrelated domains. The reason for that is a mix of (1) a never-ending reflection on the role of the university as a (regional, national and international) knowledge centre, (2) the internal and external weight put on 'accountability' and 'transparency' at all levels of the university as an 'enterprise', and (3) the expansion of a managerial middle management that is supposed to help universities in making sure that the 'accountability' and 'transparency' criteria are met. All of these factors ultimately impact on language policy and planning. In fact, the Institutional Policy Project (IPP) that was launched in 2013, an international collaborative project between policy researchers and practitioners in various English-speaking countries, deals with exactly these issues and how universities have to respond through language policy as a governance "artefact". Colleagues from the participating institutions affirm that good governance at universities demand policy review as part and parcel of policy cycles (cf. Freeman et. al. 2014). As these authors aptly put it: “(i)nstitutional policy is a contemporary issue, as institutions face increasing requirements for governance texts”, inter alia referring to the work of Ball (2010) on "the terrors of performativity" within education at large.

Taking McGill University in Montreal as a random example, a glance at that part of the website dedicated to 'University policies and regulations' that concern the university as a whole $\mathrm{e}^{1}$ currently contains 59 policies and regulations that are related to issues including the acceptance of gifts, the use of paper and smoking. The website further contains a number of links to other faculty and departmental websites where other complementary policies can be found. As far as the use of languages is concerned, McGill as an anglophone university in the francophone province of Québec 'obviously' has a 'Policy on the Use and the Quality of French' to be found among the general

1 www.mcgill.ca/secretariat/policies-and-regulations; last access on 29 January 2020. 
'University Policies and Regulations' referred to above. That part of the McGill-website targeting undergraduate students contains complementary information on McGill's language policy ${ }^{2}$. It refers to students' rights to write essays, examinations and theses in English or French in certain programs, the bilingual nature of the program offered by the Faculty of Law, English language courses for students who need to improve their language skills, French language courses for students in M.D. (Medicinæ Doctorem), C.M. (Chirurgiæ Magistrum) and D.M.D. (Doctor of Dental Medicine) programs who will be in contact with francophone patients in teaching hospitals, etc.

It seems safe to say, then, that university language policy is part and parcel of the complex and multifarious field of university policymaking. In addition to that, university language policy is in and of itself a complex and multiple-sided field, with many different ramifications (different levels, contexts of language use, stakeholders involved, etc.). We turn to these in the following section, which forms the basis of the analytical framework that we put forward in the paper.

\section{The multifaceted nature of language policies in higher education}

In view of the development of a framework that is meant to serve as a guidepost for those interested or actively involved in the design, implementation and/or evaluation of language diversity management in higher education, this section offers a general description of its transversal, multilayered, multidimensional and multiple goal-oriented nature on the basis of a synthesis of recent available LPP literature. To be in line with Kaplan and Baldauf's (1997) plea for a consideration of actual language policy and planning practices when engaging in the development and/or refinement of LPP theory and frameworks, such an approach should ideally be combined with a general content analysis of university-wide language policies at different institutions. The studies presented in this collection partly fulfil this need. It is, however, clear to us that the framework developed in this chapter would deserve to be scrutinized against the background of a detailed content analysis of a wide variety of available university language policy documents.

4.1. Language policies in higher education are transversal because they touch a wide variety of what some refer to as 'categories of communicative acts', 'missions', 'activities' or 'areas'. The communicative acts mentioned by Jernudd (2002: 299) include teaching acts, study acts, administrative acts, research acts, writing and other pres-

2 www.mcgill.ca/study/2018-2019/university_regulations_and_resources/undergraduate/gi_lang_ policy; last access on 29 January 2020. 
entation acts, service acts and governance acts. Jenkins (2013: 3) identifies teaching, research, and service functions as the "tripartite missions" of universities. Gregersen et al. (2018: 10) mention teaching, research, and communication as "the different forms of academic activity". According to Grin (2010: 8-9) universities "use languages for (essentially) five types of activities": the languages taught as subjects; the language or languages of instruction used in the teaching of other, non-linguistic subjects; the languages used by academic staff in research; the languages used by the university in its administrative operations; and the languages used by the university in its external communication. Liddicoat (2016: 232) lists teaching and learning, research and administration as "areas of academic work". A document produced by the European Language Council informs the reader that a language policy in higher education "may encompass some or all of the following principal areas: the HEI institutional language or languages; the language(s) of administration and communication; language degree programmes [...]; languages for non-language students; languages for mobility and employment; the language(s) of instruction and language support for lecturers not teaching through the medium of their own first languages; language support for researchers; language support for librarians, technicians and administrative staff; languages for the wider community" (Lauridsen 2013: 3-4).

4.2. Language policies in higher education are multilayered for two reasons. The first reason is that within each of the 'activities', 'areas', 'communicative acts' or 'missions' different layers can be distinguished that (might) require (slightly) different regulations.

- In the case of 'teaching activities', e. g., Gregersen et al. (2018: 20, 42) make a distinction between "basic educational levels" or "Bachelor level", [s]tudy programmes at Master's level” and study programmes "at PhD level” or "Post-graduate advanced study for a doctorate".

- In the area of research, Lauridsen (2013: 9) distinguishes between the language(s) in which researchers "are expected to publish or otherwise communicate the results of their research". When describing "the languages used by academic staff in research", Grin (2010: 9) makes a distinction between "(i) research activities proper, including project drafting and submission, interaction within and between research teams, and (ii) publication of scientific work in specialist journals and books or in formats destined to the general public (including in both cases on-line publication of materials)". A key point is acknowledging the fact that, in multilingual university settings, research production and dissemination can take place in multiple languages (see the case study of a university research site in Barcelona analyzed by Bretxa/Comajoan/Vila 2016). Grin (2010: 14-15) further refers to the work of the French physicist Lévy-Leblond (1996) who developed a typology for research communication based on a cross-tabulation of the categories 'written communication' and 'oral communication', on the one hand, and 'informal', 'institutional' and 'public' communication, on the other. 
- As far as more administrative communicative acts are concerned, Grin (2010: 9) distinguishes between 'internal administration' and 'external communication' (the examples he adds are recruitment and public relations).

The second reason why language policies are multilayered is that a multitude of language policy and planning actors within and outside of the university are involved in the design, implementation, interpretation, appropriation and/or the evaluation of language regulations.

- If one follows the distinction suggested by Fenton-Smith/Gurney (2016: 74) that is itself inspired by Zhao/Baldauf (2012) and Marriott (2006) it is possible to distinguish between macro-level actors (i. e. governments, government institutions, government officials and, one could add, officials, committees and lobby groups working at the supranational level such as the Academic Cooperation Association in the European realm ${ }^{3}$ ), meso-level actors (the individuals, boards and committees playing a role at the decision-making levels of central university administration), and micro-level actors (the individuals, boards and committees at the level of faculties, institutes or departments). For practical reasons, most work in university language policy research involving actors has tended to concentrate on students and teaching staff (those being more readily available for interviewing and/or observing). The focus, therefore, is usually on the point of policy interpretation, appropriation, or evaluation. However, some studies exist that have analyzed the level of policy creation and the role of committee members in bringing policy texts into existence (e.g. Källkvist/Hult 2016). In addition, ignored until recently, the role administrative staff play in implementing specific institutional policies can be determinant, particularly in connection to their attitude towards language(s) and multilingualism (see e. g. Llurda et al. 2014; Siiner 2016).

3 Founded in 1993 and comprised of 15 national organizations in 13 European countries as well as associate members in Canada, the United States of America and Mexico, ACA presents itself on its website (www.aca-secretariat.be) as a "not-for-profit pan-European network of major organisations responsible in their countries for the promotion of internationalisation in education and training". Its members "are involved in a wide range of activities in the field of internationalisation of education, with particular focus on the management of exchange programmes, promotion of national education and culture abroad, research and data collection, provision of education-related information and consultation, and formulating policy advice". One of its recurring publications is the 'state of play' of English-taught programmes in European Higher Education (Maiworm/Wächter 2014), including a section that covers the impact of such programmes on institutional policies and administrative procedures, the benefits of such programmes for students and the kind of student support services that are needed to turn the 'staying abroad experience' of incoming and outgoing students into a success. 
4.3. Language policies in higher education are multiple-goal oriented because the goals related to the activities listed in the previous point will ideally be different depending on the main language users the policy aims at. Lauridsen (2013: 5) identifies a number of target audiences including "current or future students; current or future faculty, lecturers, librarians, service and administrative staff; authorities; other HEIs [i.e. Higher Education Institutions]; local communities; the corporate sector; etc.". Students can, according to Gregersen et al. (2018: 37) be classified as "either local or international students". The latter "may be further subdivided into exchange and full-degree students”. Lauridsen (2013: 6) makes a distinction between 'local' students, students of migrant families, international exchange students and full degree international students.

4.4. Finally, language policies in higher education are multidimensional because they often cover a specific mix of the activities referred to in more traditional LPP literature, namely: (1) the status, (2) the social prestige, (3) the acquisition, and (4) the corpus of a given language or language variety. University language policies certainly involve the following:

(1) Activities that have an influence on the social status and/or the functional range of a language (variety) without necessarily having the intention of increasing the number of people actually using it, and (2) activities that have an influence on the social prestige (or, in other words: the "reputation", see Lo Bianco 2013: 3100) of a language (variety). That status and prestige are strongly connected ${ }^{4}$, is made clear by Grin (2010: 7). Writing about how "the choice of a language as a medium of instruction" is not simply a trivial choice but a choice that "matters" because it "touches upon non-material, symbolic issues with a considerable political, social and cultural content”, he adds the following theoretical example:

"the exclusion of a language (say, language $L x$ ) in favor of the use of another (say, language $L y$ ) lowers the prestige and social recognition of $L x$, depriving its native speakers of an asset (the full usability of their best language skills), with non-tangible consequences (a feeling of disenfranchisement, for example), but with tangible consequences too (the higher costs incurred, by comparison with native speakers of $L y$, to achieve academic and professional success)”.

This is an observation that pertains to discussions on, for example, the inclusion of minority languages (as opposed to majority languages) in higher education, the weight to be given to English as a 'taken-for-granted lingua franca' in teaching programs and research activities, and the attention to be given to sign language in teaching, research and administration.

4 Obviously, all 4 traditional LPP activities are interconnected. It would, however, go beyond the purpose of this chapter to deal with all these interconnections in detail. 
In terms of language status and prestige planning, university-wide language policies could endorse the practice of 'parallel language use' that also features prominently in Gregersen et al. (2018). In short, parallel language use "refers to the concurrent use of several languages within one or more areas", whereby [n]one of the languages abolishes or replaces the other" (Gregersen et al. 2018: 9) (for a critique of the political nature of the concept and its difficult practical implementation, see Kuteeva 2014). Parallel language use will mean different things within different contexts: it could, e. g., refer to the use of English and a Nordic language in the Scandinavian realm, the use of English and Dutch in The Netherlands, the use of English and Dutch, in historical South Africa, or English and Afrikaans in contemporary South Africa, etc.

(3) A third type of LPP activities are those aiming at the acquisition of a language (variety) and at increasing its number of users. In higher education such activities include the provision of "courses in the teaching language, common speech and language for special purposes" to "staff recruited abroad". Such courses feature among the policy recommendations listed in Gregersen et al. (2018), who also emphasize the importance of offering language courses to students, lecturers and researchers on the basis of a needs analysis as well as the need to develop digital language-support resources (see also Lauridsen 2013: 7-9).

(4) The final types of LPP activities mentioned in traditional LPP literature are the ones aiming at modifying the corpus of a language (variety) through the standardization and/or the elaboration of its lexicon, grammar and/or orthography. These kinds of activities might be related to the development and the adequate use of specialized (scientific and administrative) terminology in a university's official language(s) (Gregersen et al. 2018: 50).

We realize that a detailed systematic discussion of the multifaceted nature of language policies in higher education serves descriptive-pedagogical purposes. When reading existing (university-wide) language policy documents, it is sometimes hard to tell to what extent they are the result of a careful consideration of the complexity of language policies as described in LPP literature and/or an adaptation of guidelines or principles that can be found in documents produced by government bodies or university-external organizations and think tanks, or whether they are informed by meta-policy, an essential element within an increasingly regulated tertiary environment (see Freeman 2013). In other words: given the lack of publicly available background information on how language policies at universities are actually designed and monitored, it is hard to tell at first sight to what extent universities that have a university-wide language policy systematically engage(d) in all the aspects of language diversity management that is defined by Webb (2002: 281) as 


\begin{abstract}
"the entire process [...] from the strategic analysis stage (the identification and definition of the major language problems which need to be resolved, the decision about the language planning framework to be used, the analysis of the relevant external and internal environments, the description of the language planning vision and mission, and the formulation of general and specific language policy goals ...), through the strategic planning stage, that is the description of the specific plan of implementation, to the actual management of the implementation of the language policy and plan”.
\end{abstract}

One does get the impression - also when taking some university policies into account (including those referred to in the rest of the present volume) - that there still is some truth to the observation made by Elizabeth Dines, former Academic Registrar of the University of Adelaide, who - at the occasion of a forum on University Language Policy organized by the Australian Linguistic Society back in 1993 - noted:

"[a]s a policy maker, I think that it is folly to try to deal with a smorgasbord of issues which clearly are interrelated. What universities need is a way of bringing these issues together so that they can be systematically addressed within a cohesive framework and linguists are the people professionally equipped to do this." (quote taken from Kaplan/Baldauf 1997: 262; see also Clyne 2001: 214)

More recently, Grin (2010: 10) who specifically concentrates on the attention given to language policy implications, notes that "[a]vailable documents suggest that authorities merely go ahead with all kinds of language-related decisions taken with only the most tenuous grasp of their implications". He adds: “[M] ost of the time, the issues at hand are only partly identified, if at all. Generally, university authorities will take a narrow view, which amounts to making a host of assumptions, often unstated. The result is a very partial approach to language choices in university governance". It seems from the above that university-wide language policy documents are not always the result of a systematic consideration of the multifaceted nature of language-relevant issues. One can imagine that the intricate nature of language, the 'smorgasbord of issues' as stated by Dines, is part of the problem. That provides some room for a broad transparent and easily comprehensible framework that offers an overview of the main issues related to language diversity management in higher education and could help to serve as a flexible guidepost for those persons involved in the design, implementation and/or evaluation of university-wide language policy and planning. 


\section{A framework for the study of language diversity management in higher education}

The framework presented here is inspired by the detailed description of a theoretical way of dealing with the multifaceted nature of language policies in higher education presented in section 3. We first define a number of areas that are at the core of a university language policy. We then show how these areas can be subdivided into a number of layers that are linked to a number of specific goals based on the targeted audiences (we refer to them as the intended language users) that correspond to each of the layers. We subsequently identify a number of language policy activities to be considered in a language diversity management process that wants to take the multiple goals related to the multilayered domains into account, a number of broad strategic questions linked to each of those activities in order to illustrate the enormous range of challenges that universities face in terms of linguistic diversity management, and we devote attention to the actors that - in one way or another - are (in)directly involved in language policy design, implementation and/or evaluation.

The areas, layers, language users, language policy activities and policy actors as such are to be considered as the interconnected pillars of the framework. These pillars - it seems to us - are not context-specific. They rather allow to outline the contours or the dimensions of a university-wide language policy document in a great variety of higher education settings. The concrete identification of a number of specific areas, layers, language users, language policy actors and language policy activities in a specific setting is, on the contrary, subject to Haugen's (1972) principles of the ecology of language. The historical uniqueness of each setting of higher education might require an adaptation of elements that are put forward by us on the basis of elements discussed in section 3 as well as our own experience. Precisely because of the historical uniqueness of each setting, we did not consider it wise to overburden the framework with a detailed list of layers, language users and language policy actors. We opted for some 'main categories' and trust that the (strategic) language policy questions that are part of the framework will help its (future) users to adapt, complete or even reframe the framework according to their context-specific needs. We also trust that - despite the framework being open to improvements and additions - readers will see the added value of systematically addressing a 'smorgasbord' of interrelated issues in a systematic way in the form of a cohesive, yet also adaptable framework as the one presented here. 


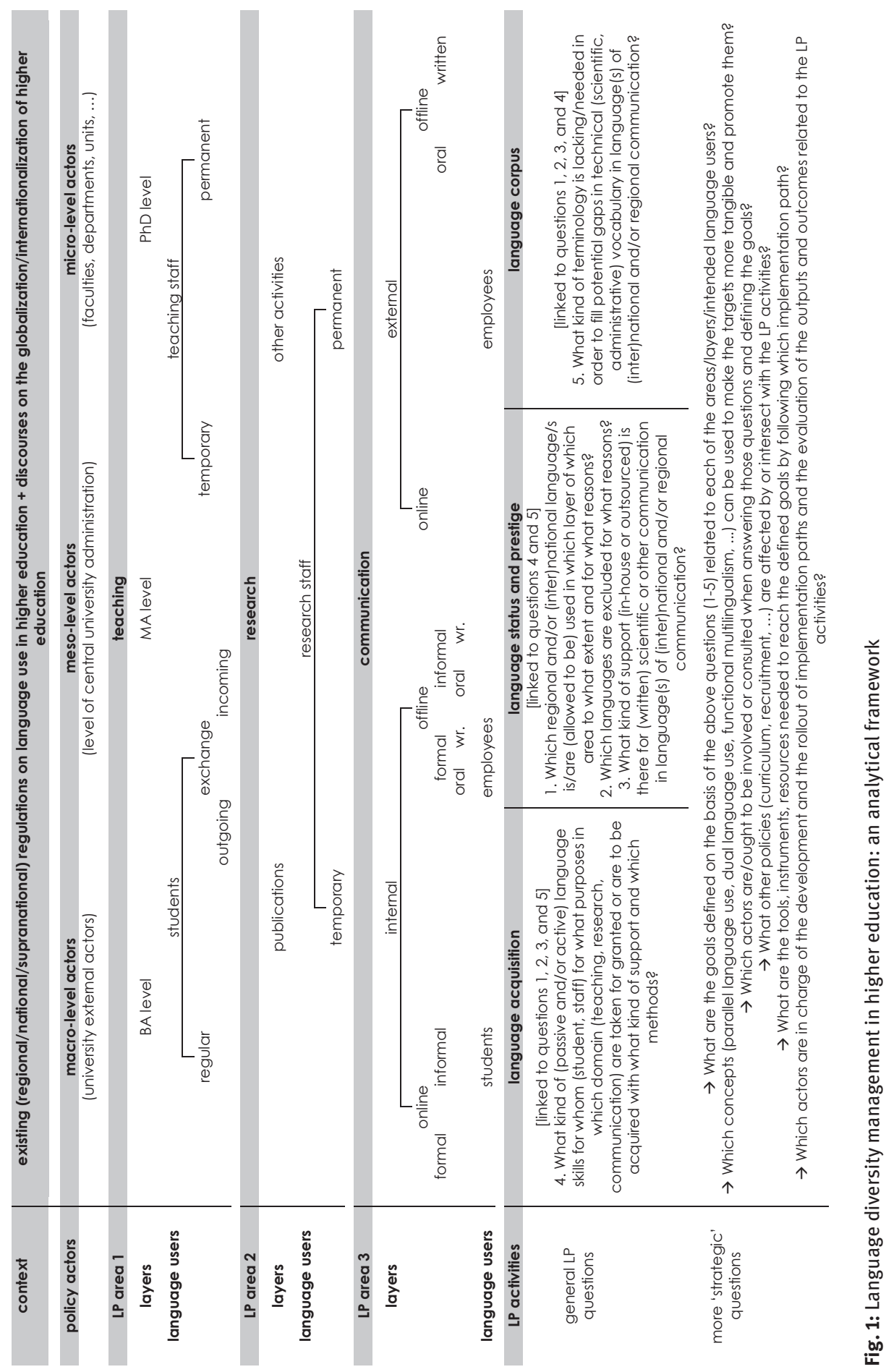




\subsection{Areas and layers}

Following Gregersen et al. (2018: 10) we chose to identify teaching, research and communication as "areas of academic work" (Liddicoat 2016: 232) and therefore also as areas of relevance to language policies in higher education. These areas play a role in the language policy documents selected for the purposes of this chapter. As to the identification of policy layers related to each of these areas we made the following choices:

- Again in line with Gregersen et al. (2018: 42) we subdivided the area of teaching into teaching at $\mathrm{BA}, \mathrm{MA}$ and $\mathrm{PhD}$ level, also because that corresponds to the common subdivisions that we are familiar with in European and South African settings (see the contributions to this volume).

- In the area of research, we make a distinction between publications and a broad category of 'other activities'. We refrained from using the grid suggested by Lévy-Lebond (1996) and summarized in Grin (2010) that is based in a cross-tabulation of 'written' and 'oral' scientific communication, on the one hand, and 'informal', 'institutional' and 'public' communication, on the other. It appears that research is the domain that is discussed in less detail in university-wide language policies. The reason for that might be that for most universities the choice of language of publication is the prerogative of the researcher and that other factors that are outside the direct control of universities (the target audiences of publications and communications, language policies of journals or even publishing houses at large, language policies of funding bodies, different sorts of journal rankings, ...) tend to influence language choices (see also Gregersen et al. 2018: 45-46).

- The area of communication is, admittedly, a very vast one. Following some current guideline documents, such as that of South Africa's Pan-South African Language Board (PanSALB 2003) and of the European Language Council Working Group on Higher Education Language Policy (Lauridsen 2013), we chose to make a distinction between internal and external communication. The lines between 'internal' and 'external' are not easy to draw in all cases of communication. Our 'definitions' of internal and external communication are therefore to be considered as broad working definitions. We consider internal communication to refer to the transmission of information 'within' the university. It essentially comes down to (offline or online, formal or informal, oral or written) communication between (those who represent) the university as an employer and one or more employees, communication between employees of the university, and communication between (those who represent) the university as an educational facility and students. In equally broad terms, (offline or online, oral or written) external communication is the transmission of information to persons (the public, prospective students, government officials, ...) who are not employed by or do not study at the university. 


\subsection{The intended language users}

Moving to the intended language users (i.e. the persons or groups of persons whose language use the policy intends to regulate) for the area of teaching, we decided to refrain from using a great variety of possible categories such as 'lecturers', 'teachers', 'foreign teachers, 'staff', 'Bachelor's students', 'incoming students', 'visiting foreign students', etc. To keep the framework as simple and transparent as possible, we chose to use two broad main categories: 'students' and 'teaching staff'.

It is tempting to classify students as "either local or international students" and the latter as either "exchange" or "full-degree students" (Gregersen et al. 2018: 37). However, instead of taking 'geographical' categories (i. e. 'local' vs. 'international') as a starting point, we opt for the distinction that (some) admission services tend to make between 'regular students' (who are enrolled or accepted for enrollment at a specific institution of higher education with the aim of obtaining a degree or a certificate offered by that institution) and 'exchange students' (who are enrolled or accepted for enrollment at a specific institution of higher education but who spend one or possibly two semesters at another institution of higher education in the context of an exchange program). The exchange students can be subdivided into 'incoming' and 'outgoing' exchange students. The latter category obviously overlaps with the category of 'regular students'. Once a regular student leaves his/her alma mater for a few months, he/she automatically becomes an outgoing exchange student. The relevance of these subgroups in terms of language policy is something that we address further below.

As far as the 'teaching staff' is concerned, we opted for this broad category since a variety of employees are involved in teaching activities, i. e. not only faculty (lecturers, senior lecturers, readers, professors), but also teaching assistants, pedagogical assistants, teaching and research assistants, etc. We again consider it useful to make use of 'administrative criteria' to identify two sub-categories, i.e.: permanent and temporary teaching staff. The reason for this is that in many contexts the kind of language skills that are required from persons with a permanent position (most certainly faculty members) are more restrictively defined than the kind of skills required from non-permanent teaching staff. A same distinction (permanent vs. non-permanent) can be applied in the case of 'research staff'. The category of non-permanent teaching and research staff includes visiting international teaching staff. That category is not mentioned in the framework so as not to overburden it.

In the case of 'administrative staff', Lauridsen (2013: 3-4) mentions categories such as librarians, technicians and administrative staff. For the purpose of our framework we did, however, not deem it useful to list staff categories linked to the area of (internal and external) communication. We chose to list employees as a general category of intended language users for both internal and external communication. For internal communication we also added students since they are also in contact with university staff members working in different areas. 


\subsection{LP activities, guiding questions and the role of different actors}

With the areas, layers and language users in mind, it becomes possible to more systematically reflect on a number of general questions that can be addressed (in total or partially) in a university-wide language policy document. The broad questions listed in the framework below are linked to the traditional LPP activities. They are not new or innovative. Similar questions can be found in Grin (2010) and Lauridsen (2013) or derived from the recommendations listed in Gregersen et al. (2018).

One of the most straightforward strategic questions for each university to answer in terms of language diversity management is the one concerning the choice of the language(s) to be used at the level of teaching, research, and internal as well as external communication (see questions 1, 2 and 3 of the framework). That choice concerns

(1) the weight that a university (in compliance with government regulations) wants to or is forced to give at the level of teaching, research and communication to a language (or potentially two or more languages) that either by law or de facto has (or have) the status and the accompanying prestige of administrative language(s) of a state or a region of the state in which the university is located, and

(2) the weight that a university (in compliance with government regulations) wants to or is allowed to give to any other language at the level of teaching, research and communication.

As it can be inferred from the language policies of universities discussed in the present volume, certain government policies do have a sometimes profound impact on language choices. In the South African context, for example, the universities' language policies during the presidency of Nelson Mandela and Tabo Mbeki were to a large extent a response to government policy on language use and social change (based on a balance between continuity and transformation) after the constitutional changes in 1994. After 2008 and to an even greater extent after 2015, some universities started to question and revise their language policy at least partly in (pro-active) response to the demands of a heterogeneous group of students (heterogeneous in terms of socio-economic backgrounds, political ideologies and party-political involvement - see Cloete 2016) for more equality and social justice. In recent years, it seems to be especially the political agenda of university-external macro-level (governmental and non-governmental) actors that had an impact on the way in which several layers of (language) policy actors at university level engaged in 'refurbishing' their university's language policy as part of a wider web of social policies aiming at 'inclusion'. So, in South Africa as well as in the European and many other contexts, a complex web of macro-level voices and policy texts exist that - together with similar or competing voices and texts 
at the meso- and the micro-level - aim at having an impact on language dynamics and (some of the) language choices in higher education, as the contributions to this volume confirm.

Obviously, the choices related to the use of one or more languages need not be symmetrical for each of the areas (i.e. teaching, research and communication), need not be as regulated for one area or sub-layer within an area compared to another area or sub-layer within an area, and can be motivated in a variety of ways (with reference, for example, to the overall status and prestige of a language in academia, in a certain academic discipline or in a certain (part of a) country or region). While it can make sense to emphasize the importance of teaching in a certain language in a certain context in relation to a certain subject, it might make less sense to try and regulate the use of certain languages to be used in publications since - as mentioned in section 3 - that obviously depends on a variety of factors that are beyond the control of universities. However, that does not mean that one could not encourage researchers to publish in other languages in consideration of national or international conditions or to encourage them to be guided in their decisions by considerations such as the purpose of the research report, the intended readership and ultimately the target audience. Given the great variety of practices that exist when comparing the Social Sciences and Humanities with Life Sciences and Natural Sciences, a university-wide policy can be used to put forward a number of general principles (some of them potentially linked to general concepts such as 'parallel language use', 'functional multilingualism', 'receptive multilingualism', ...) and to delegate more specific choices related to language use in teaching and research to the level of faculties, units and the like (see also Gregersen et al. 2018: 31).

Ideally, the choice for one or more 'other' languages in specific areas of teaching or research - a choice that, at least in theory, can have a positive effect on the status, the functional range and the reputation of that or those language(s) - will be backed-up by activities that help to guarantee a high-quality use of the 'chosen' languages in those areas. If, for example, a university considers to allow for the use of a certain language (that differs from the administrative language(s) of a state or a region of the state in which the majority of the regular students attending a university were educated) as a language of instruction, then the following questions (derived from questions 3 and 4 in the framework) might help to identify a number of activities that need to be developed in line with the language choice that is (to be) made:

(1) what kind of skills and proficiency levels do regular (and other) students need to have in order to be able to enroll for such a program,

(2) what kind of support structures and language acquisition methods and techniques is the university willing to put into place in order to enable students within a reasonable amount of time to acquire the necessary skills needed to enroll for such a program, 
(3) what kind of skills and proficiency levels do the university teachers need to have in order to be able to teach a class in a language that is not their first language,

(4) what kind of support structures and language acquisition methods and techniques is the university willing to put into place in order to enable university teachers to offer quality education in a language that is not their first language, and

(5) what kind of assessment criteria is a university willing to use to test the skills of both students and university teachers?

Similar kinds of questions pertain to incoming and outgoing exchange students that within the framework of Erasmus+ or another student mobility program - decide to enroll for a number of courses (offered in a language that differs from their native language) at a partner university of their home university. Here the question is if and how those students' home university and/or those students' host university are willing to invest in the necessary measures that will (1) help these students to acquire the necessary skills that will allow them to take full advantage of their 'study abroad adventure', and (2) make sure that the persons with whom they will be in contact at the host institution (teaching staff and administrative staff) have the necessary skills to be of assistance to those students.

Especially in terms of internal communication with incoming mobility students, teachers and researchers, universities need to carefully consider the kinds of language repertoires and skills not only of the staff allocated to the international office, but also of staff working in the registration office, the educational administration, the housing service, the HR-service, etc. Especially the so-called 'front-line employees' (or key personnel) might need good 'foreign language' skills when it comes to oral communication. In terms of written communication, certain tools exist that offer free and online translation services. Although they might not yet suffice to automatically translate entire parts of the information available on websites, let alone scientific publications, such services do facilitate a form of 'virtual parler bilingue' or, more generally, a form of 'receptive multilingualism' at surface level. That brings up the question to what extent a university invests in resources allowing for the professional translation of, for example, administrative documents or parts of its website in (an)other language(s) than the administrative language(s) of a state or a region of the state in which it is located, or scientific publications in other languages than the native language of the authors of such publications. It also brings up the question if a university, when making use of translations to ascertain a certain degree of linguistic diversity in line with the language choices referred to above, considers translation as an in-house activity that is part of the additional tasks of a language center or rather as an activity that is so specific that it deserves to be outsourced. If it considers translation to be an important element of life at the contemporary university that is both a local/regional/national and an international player, yet another additional question that emerges is to what extent 
a university - even apart from all possible government regulations that might exist considers it to be part of its duty to actively contribute to the cultivation and elaboration of a scientific vocabulary in the language that equals the administrative language(s) of a state or a region of the state in which it is located (see question 5 in the framework).

The fact that the preceding paragraph mentions 'front-line employees' (as opposed to other employees) and also mentions the outsourcing of translation services as a possible scenario to deal with language demands already indicates that (re-) designing a university language policy requires thinking about the way it is related to other policies. To the example of language-in-education policies, language policies in higher education also require "a variety of related policies for effective implementation", ranging from personnel policy over curriculum policy to resourcing policy (see Fenton-Smith/Gurney 2016: 73). It is the task of those involved in the design of a university-wide language policy that the policy (and the policies at faculty or other level that derive from it) take other existing (personnel, curriculum, etc.) policies into account and either adjust the language policy to those existing policies or readjust the other policies in function of the goals and the desired outputs and outcomes of the language policy. It is, therefore, a good idea to make a department, a directorate, a unit, or a policy officer responsible for the language policy. The responsibilities include: the coordination of the language policy formulation process in which different meso- and micro-level actors are involved; the definition of certain targets related to certain areas and intended language users; the identification of tools and instruments needed to reach the defined goals; the rollout of the policy implementation pathway; and the evaluation of the outputs and outcomes related to the language policy activities (see the list of strategic question in the framework). Gregersen et al. (2018: 30) emphasize that "[s]omeone must be responsible for implementing the policy once it has been drawn up, and the policy must be firmly embedded in the university management to facilitate regular revision and follow-ups. Otherwise, there is a risk that the policy becomes a dead document full of good intentions”. They also stress that "[f]irst and foremost, a language policy must set out the general principles to be used in particular cases by those who are faced with a decision on which language to use for reading materials, teaching or (formal or informal) meetings. It is not the purpose of a language policy to remove decision-making power or responsibility from those concerned."

\section{Conclusion}

The concerns or 'warnings' expressed by Gregersen et al. (2018) make it all the more necessary and potentially rewarding to study the actual practical management of language policy processes at university level in more detail. While there is a variety of sources available that can be of help in finding answers to specific questions related 
to activities that concern the acquisition, status, prestige, and the corpus of languages as they are used at universities (see the literature overview in section 2), the actual administrative management of language policy processes at universities remains underexposed. The framework presented in this paper is therefore nothing but a first step towards a more detailed study of the practical administrative challenges that university administrators are faced with when thinking about or rethinking the language dynamics of their institutions.

\section{References}

Ammon, Ulrich (1988): Deutsch als Publikationssprache der Wissenschaft: Zum Umfang seiner Verwendung im Vergleich mit anderen Sprachen. In: Germanistische Mitteilungen 28, 69-82.

Ammon, Ulrich (1998): Ist Deutsch noch internationale Wissenschaftssprache? Englisch auch für die Lehre an den deutschsprachigen Hochschulen. Berlin/New York: De Gruyter.

Ammon, Ulrich (2000): Entwicklung der deutschen Wissenschaftssprache im 20. Jahrhundert. In: Debus, Friedhelm/Kollmann, Franz Gustav/Pörksen, Uwe (eds.): Deutsch als Wissenschaftssprache im 20. Jahrhundert. Mainz/Stuttgart: Akademie der Wissenschaften und der Literatur/ Franz Steiner Verlag, 59-80.

Austin, Ian/Jones, Glen E. (2016): Governance of higher education: Global perspectives, Theories, and Practices. London: Routledge.

Ball, Stephen (2010): The teacher's soul and the terrors of performativity. In: Journal of Education Policy 18, 2, 215-228.

Barnard, Roger/McLellan, James (eds.) (2013): Codeswitching in university English-medium classes: Asian perspectives. Bristol: Multilingual Matters.

Bergan, Sjur (ed.) (2002): Language policies in higher education: Invitation to a debate. Strasbourg: Council of Europe Publishing.

Bhambra, Gurminder K./Gebrial, Dalia/Nişancıoğlu, Kerem (2018): Decolonising the university. London: Pluto Press.

Björkman, Beyza (2013): English as an academic lingua franca: An investigation of form and communicative effectiveness. Berlin: De Gruyter Mouton.

Block, David (ed.) (2016): Internationalisation policies and practices in European universities: Case studies from Catalonia (= The Language Learning Journal 46, 3). London: Routledge.

Bretxa, Vanessa/Comajoan, Llorenç/Vila, F. Xavier (2016): Is science really English monoglot? Language practices at a university research park in Barcelona. In: Language Problems and Language Planning 40, 1, 47-68.

Charle, Christophe/Verger, Jacques (2012): Histoire des universités. XIle-XXIe siècle. Paris: Presses Universitaires de France.

Cloete, Nico (2016): A 'third force' in higher education student activism. University World News. The Global Window on Higher Education, 4 March 2016. https://www.universityworldnews.com/ post.php?story=2016030410040021 (last accessed 3 April 2020).

Clyne, Michael G. (2001): Micro language policy as a barometer of change: A university language policy as an example. In: Cooper, Robert L./Shohamy, Elana/Walters, Joel (eds.): New perspectives and issues in educational language policy. Amsterdam: John Benjamins, 211-234.

Cots, Josep M./Llurda, Enric/Garrett, Peter (2014): Language policies and practices in the internationalization of higher education on the European margins: an introduction. In: Journal of Multilingual and Multicultural Development 35, 4, 311-317. 
Curaj, Adrian/Deca, Ligia/Pricopie, Remus (eds.) (2018): European higher education area: The impact of past and future policies. Cham: Springer Open.

D'Hertefelt, Margot/De Wachter, Lieve/Verlinde, Serge (2014): Writing Aid Dutch. Supporting students' writing skills by means of a string and pattern matching based web application. In: Zvacek, Susan/Restivo, Maria Teresa/Onohuome Uhomoibhi, James/Helfert, Markus (eds.): CSEDU 2014 - Proceedings of the 6th International Conference on Computer Supported Education, Volume 1. SciTePress, 486-491

Darquennes, Jeroen (2013): Current issues in LPP research and their impact on society. In: AlLA Review 26, 11-23.

du Plessis, Theo (2006): From monolingual to bilingual higher education: the repositioning of historically Afrikaans-medium universities in South Africa. In: Language Policy 5, 1, 87-113.

du Plessis, Colleen (2016): Inferences from the Test of Academic Literacy for Postgraduate Students (TALPS). In: Southern African Linguistics and Applied Language Studies 34, 1, 1-16.

Fairclough, Norman (1993): Critical discourse analysis and the marketization of public discourse: The universities. In: Discourse \& Society 4, 2, 133-168.

Fenton-Smith, Ben/Gurney, Laura (2016): Actors and agency in academic language policy and planning. In: Current Issues in Language Planning 17, 1, 72-87.

Frank-Van Westrienen, Anna (1983): De Groote Tour. Tekening van de educatiereis der Nederlanders in de zeventiende eeuw. Amsterdam: Noord-Hollandsche Uitgeversmaatschappij.

Frank, David John/Meyer, John W. (2007): Worldwide expansion and change in the university. In: Krücken, Georg/Kosmützky, Anna/Torka, Marc (eds.): Towards a multiversity? Universities between global trends and national traditions. Bielefeld: transcript, 19-44.

Freeman, Brigid (2013): Benchmarking Australian and New Zealand university meta-policy in an increasingly regulated tertiary environment. In: Journal of Higher Education Policy and Management 36, 1, 74-87.

Freeman, Brigid/Capell, Nancy/Goldblatt, Andrew/Lapan, Miskus/Mafile'o, Tracie/Thompson, Sue (2014): An international comparative perspective on institutional policy to enhance institutional governance, policy-making and policy infrastructure, for improved institutional outcomes. Paper delivered at the Association of University Administrators (AUA) Annual Conference, University of Manchester, UK, April 13-16, 2014.

Gazzola, Michele (2012): The linguistic implications of academic performance indicators: General trends and case study. In: International Journal of the Sociology of Language 216, 131-156.

Gordin, Michael D. (2017): Scientific Babel: The language of science from the fall of Latin to the rise of English. London: Profile Books.

Gregersen, Frans et al. (2018): More parallel, please! Best practice of parallel language use at Nordic Universities: 11 recommendations. Copenhagen: Nordisk Ministerråd.

Grin, François (2010): Managing languages in academia: Pointers from education, economics and language economics. Paper presented at the conference Professionalising Multilingualism in Higher Education, Luxembourg, 4 February 2010.

Haberland, Hartmut/Mortensen, Janus (eds.) (2012): Language and the international university (=International Journal of the Sociology of Language 216). Berlin: De Gruyter.

Haugen, Einar (1972): The Ecology of Language. In: Dil, Anwar S. (ed.): The Ecology of Language. Stanford, CA: Stanford University Press, 325-339.

Hult, Francis (2016): More than a lingua franca: Functions of English in a globalised educational language policy. In: Language, Culture and Curriculum 30, 3, 265-282.

Hyland, Ken/Shaw, Philip (eds.) (2016): The handbook of English for academic purposes. London: Routledge. 
Irrgang, Stephanie (2002): Peregrinatio academica: Wanderungen und Karrieren von Gelehrten der Universitäten Rostock, Greifswald, Trier und Mainz im 15. Jahrhundert. Wiesbaden: Steiner.

Jenkins, Jennifer (2013): English as a Lingua franca in the international university: The politics of academic English language policy. Abingdon: Routledge.

Jernudd, Björn H. (2002): Managing languages at bilingual universities: relationships between universities and their language environment. In: Li Wei/Dewaele, Jean-Marc/Housen, Alex (eds.): Opportunities and challenges of bilingualism. Berlin: De Gruyter Mouton, 297-309.

Kaplan, Robert B./Baldauf, and Richard B. (1997): Language planning: from practice to theory. Clevedon: Multilingual Matters.

Kiedron, Stefan (1992): Poolse studenten in Leiden in de 16de en de 17de eeuw. In: Predota, Stanislaw (ed.): Studia Neerlandica et Germanica. Wrocław: Uniw. Wrocławskiego, 189-204.

Kuteeva, Maria (2014): The parallel language use of Swedish and English: The question of 'nativeness' in university policies and practices. In: Journal of Multilingual and Multicultural Development 35, 4, 332-344.

Källkvist, Marie/Hult, Francis (2016): Discursive mechanisms and human agency in language policy formation: Negotiating bilingualism and parallel language use at a Swedish university. In: International Journal of Bilingual Education and Bilingualism 19, 1, 1-17.

Lauridsen, Karen M. (2013): Higher Education Language Policy. CEL-ELC Working Group. Available online: www.celelc.org (last access on 29 January 2020).

Lévy-Leblond, Jean-Marc (1996): La pierre de touche (la science à l'épreuve). Paris: Seuil.

Liddicoat, Anthony J. (2016): Language planning in universities: teaching, research and administration. In: Current Issues in Language Planning 17, 3-4, 231-241.

Linn, Andrew (2015): English in Europe series preface to English-medium instruction in European higher education, edited by S. Dimova, A. K. Hultgren, and C. Jensen, vii-viii. Boston/Berlin: De Gruyter. https://doi.org/10.1515/9781614515272-001

Lo Bianco, Joseph (2013): Language policy and planning: Overview. In: Chapelle, Carol A. (ed.): The Encyclopedia of Applied Linguistics. Oxford: Wiley-Blackwell, 3094-3101.

Llurda, Enric/Cots, Josep M./Armengol, Lurdes (2014): Views on multilingualism and internationalisation in higher education: Administrative staff in the spotlight. In: Journal of Multilingual and Multicultural Development 35, 4, 376-391.

Maiworm, Friedhelm/Wächter, Bernd (eds.) (2014): English-Taught programmes in European higher education. The state of play in 2014. Bonn: Lemmens.

Mansoor, Sabiha (2005): Language planning in higher education. A case study of Pakistan. Oxford: Oxford University Press.

Marriott, Helen (2006): Micro language planning for student support in a pharmacy faculty. In: Current Issues in Language Planning 7, 2-3, 328-340.

Martyniuk, Waldemar (2010): Alligning tests with the CEFR: Reflections on using the Council of Europe's draft manual. Cambridge: Cambridge University Press.

PanSALB (Pan-South African Language Board) (2003): Guidelines on the layout of a language policy document for institutions for higher education. Pretoria: Pan-South African Language Board.

Purser, Lewis (2000): The bilingual university - general reflections on its origins, mission, and functioning. In: Higher Education in Europe XXV, 4, 451-458.

Rüegg, Walter (ed.) (2011): A history of the university in Europe. Vol. IV: Universities since 1945. Cambridge: Cambridge University Press.

Siiner, Maarja (2016): University administrators as forced language policy agents. An institutional ethnography of parallel language strategy and practices at the University of Copenhagen. In: Current Issues in Language Planning 17, 3-4, 441-458. 
Soler, Josep/Gallego-Balsà, Lídia (2019): The sociolinguistics of higher education. Language policy and internationalisation in Catalonia. Basingstoke: Palgrave macmillan.

Soler, Josep (2019): Language policy and the internationalization of universities. A focus on Estonian higher education. Berlin: De Gruyter Mouton.

Tollefson, James W./Pérez-Milans, Miguel (2018): The Oxford handbook of language policy and planning. Oxford: Blackwell.

Van de Poel, Kris/van Dyk, Tobie/Gasiorek, Jessica/Blockmans, Inge (2015): A needs analysis for communication by pharmacists in a multilingual setting: first steps towards syllabus and materials design. In: Stellenbosch papers in linguistics 44, 189-212.

Van Leeuwen, Charles/Wilkinson, Robert (eds.) (2003): Multilingual approaches in university education. Challenges and practices. Nijmegen: Valkhof.

Van der Walt, Christa (2013): Multilingual higher education. Beyond English medium orientations. Bristol: Multilingual Matters.

Veronesi, Daniela/Nickenig, Christoph (2009): Bi- and multilingual universities: European perspectives and beyond: Conference proceedings Bolzano-Bozen, 20-22 September 2007. Bozen-Bolzano: Bozen-Bolzano University Press.

Vila, Xavier F./Bretxa, Vanessa (eds.) (2015): Language policy in higher education. The case of medium-sized languages. Bristol: Multilingual Matters.

Webb, Vic (2002): Language in South Africa. The role of language in national transformation, reconstruction and development. Amsterdam: John Benjamins.

Welch, Anthony (2005): From peregrinatio academica to global academic: The internationalisation of the profession. In: Welch, Anthony (ed.): The professoriate: Profile of a profession. Dordrecht: Springer Netherlands, 71-96.

Zhao, Shouhoui/Baldauf, Richard B. (2012): Individual agency in language planning: Chinese script reform as a case study. In: Language Problems \& Language Planning 36, 1, 1-24. 